\title{
Wear Behaviour and Cutting Performance of Surfaced Inserts for Wood Machining
}

\author{
Regita Bendikiene , $^{*}$ - Gintaras Keturakis ${ }^{1}$ - Tilmute Pilkaite ${ }^{1}$ - Edmundas Pupelis ${ }^{2}$ \\ ${ }^{1}$ Kaunas University of Technology, Faculty of Mechanical Engineering and Design, Lithuania \\ 2 Kaunas University of Technology, Laboratory Centre, Lithuania
}

\begin{abstract}
Machining, in general, and wood machining, in particular, are complex to explain and many factors influence the process. Natural wood is a nonhomogeneous biological material, so each species of wood requires different machining conditions and tools. Understanding the properties of wood and choosing the proper cutting tools and machining parameters can improve the quality of wooden products, increase production efficiency, and improve machining. The objective of this study was to find the most suitable cutting tools for the machining of oak wood grown in Lithuania. This paper describes tests of two commercial cutting inserts made of high speed tool steel (CT01M-LA2 and 8X6FT) and two experimental inserts (EI) made by surfacing using a submerged arc welding (SAW) technique and a mixture of alloying elements spread on the surface under industrial flux. The results obtained from the milling tests demonstrated the suitability of the suggested surfaced inserts for machining oak wood. All tool wear parameters, such as cutting edge radius, edge recession, nose width, and cutting power, have been evaluated and compared. The cutting edge radius of El after $3200 \mathrm{~m}$ of cutting length was $~ 5.00 \mu \mathrm{m}, 3$ to 4 times lower than the wear of standard tools; similarly, the edge recession of the surfaced inserts showed 2 to 3 times lower results. The results of this study indicate that the cutting power increases as the feed per cutter increases. These findings suggest that surfaced inserts can replace the commercial inserts used for wood machining.
\end{abstract}

Keywords: wood milling, surfacing, edge recession, tool wear, oak

Highlights

- $\quad$ Cutting tool inserts were made by surfacing using a submerged arc welding (SAW) technique.

- Wear behaviour of the presented inserts was compared with commercial inserts.

- Tests were performed on samples of oak wood.

- $\quad$ Surfaced inserts showed better wear behaviour and cutting performance.

- The suggested technology can be used for manufacturing wood machining tools.

\section{O INTRODUCTION}

The literature has emphasized the importance of both wood cutting technology and the natural properties of wood. Machining of different species of natural wood (oak, pine, birch, etc.) and timber products requires the usage of high quality cutting tools. Each type of material requires different machining conditions, so it is not possible to use one type of cutting tool to achieve the best efficiency. A number of authors have claimed that high quality tools are necessary due to the particular properties of the natural materials machined, such as the possible significant anisotropy of the structure and the cutting behaviour of the material in different directions (along or across to the fibres), large sizes (for the initial processing from the $\operatorname{logs}$ ), unexpected changes in the structure and a sudden rise in the internal stresses of the material machined, the appearance of hard and brittle particles and changes in density in a cross section, etc. [1] and [2].

Cutting tools employed in the field of wood machining do not allow the full potential of the machines to be fulfilled [3]. Several reports have shown that the main problems in wood processing arise due to differences in the physical and chemical structure of wood and metal. Firstly wood has relatively good machinability allowing high cutting and feed speed; but it contains some water, making it very corrosive [3] and [4]. Secondly, the natural defects (knots, wane, particles of hard mineral contamination, etc.) present in the timber can initiate blunting of the cutting edges; therefore, very hard but brittle materials are not suitable as cutting tools in this case. Hardened steels, high speed tool steels, stellites, tetrahedral amorphous carbon, composites of titanium carbides and polycrystalline diamond wood cutting tools are currently used in the wood industry; among them, the most common are cemented carbides, because of their good wear resistance and relatively low cost compared to diamond based tools [1] and [5]. All of the studies reviewed here support the hypothesis that cutting tools manufactured from high speed tool steel or surfaced with high wear resistance coatings can replace expensive tools made of sintered carbides or sintered polycrystalline diamond [6].

Finally, machining of wood is performed under a very high working speed and extremely sharp 
cutting edges are needed. Thus far, previous studies have reported that the main wear mechanism is the erosion of the cutting tool material; hence, coatings for woodworking tools should be very hard, adherent and smooth and exhibit high wear resistance [5] and [7]. Another problem is the rounding of the cutting edge radius during the cutting process. Even a small increase in the edge radius leads to increased tool wear and worse surface quality of the final wood product.

Thus this paper presents the results of wear behaviour of two standard cutterhead inserts, made of high speed tool steels for wood cutting, supplemented by test results of experimental inserts (EI) surfaced using submerged arc welding (SAW) technique and a properly chosen chemical composition of alloying flux.

\section{METHODS}

The base material for surfacing was cheap plain carbon steel (C $0.14 \%$ to $0.22 \%$; Si $0.12 \%$ to $0.13 \%$, Mn $0.4 \%$ to $0.65 \%, \mathrm{~S} \leq 0.05 \%, \mathrm{P} \leq 0.04 \%$ ) provided as an $8 \mathrm{~mm}$ thick plate. The surfacing process was performed on $40 \mathrm{~mm} \times 100 \mathrm{~mm}$ samples in a single pass using the SAW technique with alloying materials mixture $(\sim 6 \mathrm{~g})$ spread on the surface under the flux. The chemical composition of the materials mixture is presented in Table 1.

A single $1.2 \mathrm{~mm}$ diameter electrode low carbon wire $(\mathrm{C}<0.1 \%$; $\mathrm{Si}<0.03 \%$, Mn $0.35 \%$ to $0.6 \%$, $\mathrm{Cr}<0.15 \%, \mathrm{Ni}<0.3 \%$ ) was used for the surfacing. The SAW was carried out with an automatic welding device (torch MIG/MAG EN 500 78), with welding parameters: welding current 180 A to $200 \mathrm{~A}$, voltage $22 \mathrm{~V}$ to $24 \mathrm{~V}$, travel speed $14.4 \mathrm{~m} / \mathrm{h}$, and the wire feed rate $25.2 \mathrm{~m} / \mathrm{h}$.

Table 1. Chemical composition of the spread materials mixture

\begin{tabular}{lccccc}
\hline & \multicolumn{4}{c}{ Composition of materials mixture [wt.\%] } & \multirow{2}{*}{ Flux } \\
\cline { 2 - 5 } & $\mathrm{SiC}$ & $\mathrm{Cr}$ & $\mathrm{W}$ & $\mathrm{Fe}-70 \% \mathrm{Mn}$ & \\
\hline El & 40 & 10 & 40 & 10 & AMS1* \\
\hline * LST EN $10204: 2004 \mathrm{SiO}_{2}$ and $\mathrm{Mn0}>50 \%$ & & \\
\hline
\end{tabular}

A blended powder of materials was spread on the surface of the base metal and fused using a metal arc. Additional standard flux AMS1 (GOST 9087-81; $\mathrm{SiO}_{2} 38 \%$ to $44 \%, \mathrm{MnO} 38 \%$ to $44 \%, \mathrm{CaF}_{2} 6 \%$ to $9 \%, \mathrm{CaO}<6.5 \%, \mathrm{MgO}<2.5 \%, \mathrm{Al}_{2} \mathrm{O}_{3}<5 \%, \mathrm{Fe}_{2} \mathrm{O}_{3}$ $<2 \%, \mathrm{~S}<0.15 \%, \mathrm{P}<0.15 \%)$ was used to shield and to protect the welding area.

The presence of chromium in the surfaced layer affects the formation of the retained austenite, thus slowing the decomposition of austenite, since chromium provides some corrosion resistance. Silicon carbide ( $\mathrm{SiC}$ ) was used as a deoxidizer in the welding flux. Deoxidizers react with oxygen at the welding temperature and significantly decrease the quantity of oxides in the bead, thus increasing the quality of the weld. Adding silicon into the flux improves the metal mass transfer coefficient and the form of the weld, as well as modifying the slag [7].

One testing lot of surfaced inserts were heated to $1100{ }^{\circ} \mathrm{C}$ afterwards and hammered in order to examine the influence of plastic deformation on the wear properties of the tool. During hot hammering, the face of the surfaced samples was plastically deformed and flattened to the level of the base metal and, as a result, the time of insert machining was reduced (no additional cutting needed). The second positive outcome of the smithing process was the self-hardening of inserts in the air, i.e. tempering following hot plastic deformation. The hardness of surfaced inserts reached $60 \mathrm{HRC}$, while the surfaced and hammered reached $50 \mathrm{HRC}$. After tempering at $500{ }^{\circ} \mathrm{C}$, the hardness values were changed to $57 \mathrm{HRC}$ and $55 \mathrm{HRC}$, respectively.

The mechanical behaviour of surfaced experimental inserts and commercial inserts was assessed in terms of hardness and wear properties. Table 2 shows the chemical composition of commercial inserts. Hardness measurements of the layers were accomplished on the wrought and heattreated (tempered) inserts using Rockwell tester TK -2 at a load of $1470 \mathrm{~N}$ using a diamond indenter.

Table 2. Chemical composition of commercial inserts

\begin{tabular}{|c|c|c|c|c|c|c|c|c|}
\hline \multirow{2}{*}{ Steel } & \multicolumn{8}{|c|}{ Quantity of elements [wt \%] } \\
\hline & C & $\mathrm{Cr}$ & Mo & $\mathrm{Ni}$ & $\mathrm{Ti}$ & V & W & Co \\
\hline 1 * & 0.80 & 5.87 & - & 0.91 & 0.10 & 0.20 & - & - \\
\hline $2 * *$ & 1.00 & 3.83 & 0.21 & 0.12 & - & 2.60 & 12.55 & 0.12 \\
\hline \multicolumn{5}{|c|}{ * 8X6FT (GOST 6567-75) } & \multicolumn{4}{|c|}{${ }^{\star *}$ Freud CT01M-LA2 } \\
\hline
\end{tabular}

The most important characteristics (Fig. 1) selected to define the wear behaviour of inserts were: cutting edge radius $\rho[\mu \mathrm{m}]$, edge recession $A_{\mu},[\mu \mathrm{m}]$, nose width $b[\mu \mathrm{m}]$, and cutting power $P[\mathrm{~W}][8]$.

The actual values of the edge rounding radius were assessed using a lead imprint method with a Nikon Eclipse E200 optical microscope and Lumenera Infinity 1 digital camera. Infinity Analyze Release 5.0.2 software was used to analyse and evaluate the obtained results with an accuracy of $\pm 2 \mu \mathrm{m}$. The experimental results were subjected to statistical analysis. Cutting power $P$ was determined by measuring the available power and taking out the idle 
motion power. Available and idle motion power were measured with an accuracy of $\pm 10 \mathrm{~W}$ on a universal power tester K506.

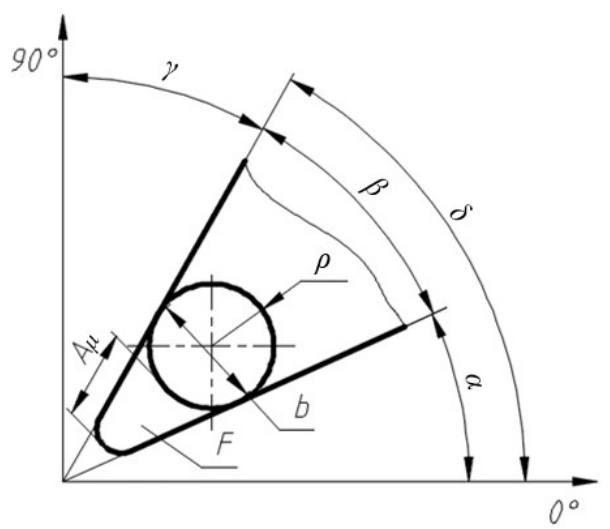

Fig. 1. The main geometrical parameters of the cutting tool: cutting angle $\delta$, sharpness angle $\beta$, rake angle $\gamma$, and clearance angle $\alpha$

The values of the cutting edge radius, edge recession, nose width, and cutting power were recorded and measured at intervals of cutting length $L:(0 ; 50 ; 100 ; 150 ; 200 ; 400 ; 800 ; 1200 ; 1600 ; 2400$, and 3200$) \mathrm{m}$. Each value at every specified cutting length was an average of 5 tests.

\section{EXPERIMENTAL}

Experimental inserts were strait sharpened and their edges were converged according general grinding procedures for inserts. The sequence of inserts manufacturing is presented in the Fig. 2.

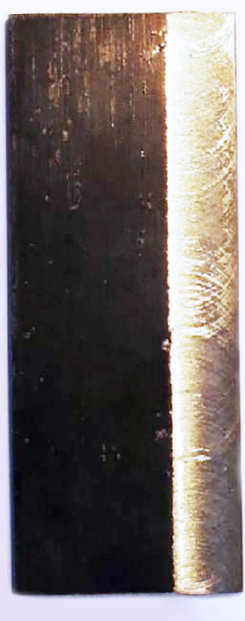

a)

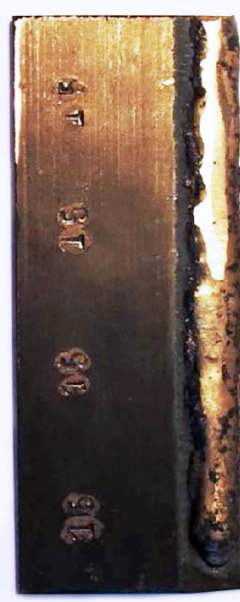

b)

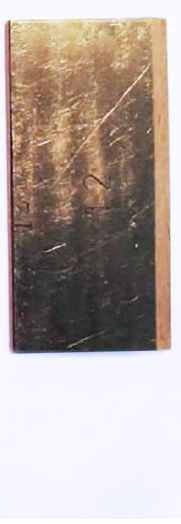

c)
Fig. 2. Sequence of experimental inserts preparation: a - blank; b - surfaced; c - insert
Table 3. Characteristics of inserts

\begin{tabular}{|c|c|c|}
\hline Characteristic & El1 * & $\mathrm{El} 2$ \\
\hline Not tempered & 50 & 60 \\
\hline After tempering & 55 & 57 \\
\hline Dimensions [mm] & \multicolumn{2}{|c|}{$60 \times 30 \times 3.55$} \\
\hline Sharpness angle $\beta$ [degree] & \multicolumn{2}{|c|}{40} \\
\hline Weight of insert $m$ [g] & 45.69 & 45.19 \\
\hline Roughness of rake face $R_{a}[\mu \mathrm{m}]$ & 0.135 & 0.152 \\
\hline Roughness of clearance face $R_{a}[\mu \mathrm{m}]$ & 0.083 & 0.066 \\
\hline
\end{tabular}

Ten wood test samples were prepared from oak wood (Quercus robur) grown in Lithuanian (Table 4) with dimensions of $1000 \mathrm{~mm} \times 100 \mathrm{~mm} \times 45 \mathrm{~mm}$. Special care was taken to select samples as free as possible of knots or other defects.

The characteristics of experimental inserts are presented in Table 3. Hereafter accurate dimensions of inserts were ensured by measuring inserts using electronic callipers with an accuracy of $\pm 0.001 \mathrm{~mm}$. The surface roughness tester, profilotemer Mahr MarSurf PS 1, was used to evaluate the roughness of the rake face and clearance face [9].

Table 4. Physical properties of Quercus robur

\begin{tabular}{|c|c|c|c|}
\hline $\begin{array}{c}\text { Average } \\
\text { moisture } \\
\text { content } \omega[\%]\end{array}$ & $\begin{array}{c}\text { Average number } \\
\text { of annual rings } \\
\text { per } 1 \mathrm{~cm}\end{array}$ & $\begin{array}{c}\text { Average width } \\
\text { of annual ring } \\
\text { [mm] }\end{array}$ & $\begin{array}{l}\text { Average } \\
\text { density } \\
{\left[\mathrm{kg} / \mathrm{m}^{3}\right]}\end{array}$ \\
\hline 10.2 & 3.00 & 3.33 & 690 \\
\hline
\end{tabular}

The average moisture content was estimated using a Gann Hydrometer Compact A electronic moisture tester with an accuracy of $\pm 1 \%$. The number of annual rings per $1 \mathrm{~cm}$ was determined by counting the rings in the end section perpendicular to the wood fibers [8]. Samples were weighted on electronic scales (accuracy $\pm 0.01 \mathrm{~g}$ ) for determination of density. Average ambient temperature of wood samples testing was $18 \pm 2{ }^{\circ} \mathrm{C}$, while relative air humidity was $60 \pm 5 \%$

Table 5. Milling test conditions

\begin{tabular}{|c|c|c|}
\hline \multirow{2}{*}{ Name } & \multicolumn{2}{|c|}{ Values } \\
\hline & El1 & $\mathrm{El} 2$ \\
\hline Cutting speed $n_{c}[\mathrm{~m} / \mathrm{s}]$ & \multicolumn{2}{|c|}{31} \\
\hline Feed per insert $f_{z}[\mathrm{~mm}]$ & 1.00 & 0.50 \\
\hline Feed speed $v_{f}[\mathrm{~m} / \mathrm{min}]$ & 6 & 3 \\
\hline Depth of milling $h[\mathrm{~mm}]$ & \multicolumn{2}{|c|}{2} \\
\hline Milling width $b$ [mm] & \multicolumn{2}{|c|}{45} \\
\hline Diameter of cutterhead $d,[\mathrm{~mm}]$ & \multicolumn{2}{|c|}{103} \\
\hline Number of inserts $z$ [unit] & \multicolumn{2}{|c|}{1} \\
\hline Cutting angle $\delta$ [degree] & \multicolumn{2}{|c|}{60} \\
\hline
\end{tabular}


The wear performance of experimental and standard inserts was carried out on a typical industrial thickness planer (SR3-6) with a face milling cutterhead using oak samples as the workpiece. The milling was conducted according longitudinal milling, with vectors of cutting speed nc and feeding speed nf. Milling conditions were the same for each of the tested inserts and are shown in Table 5.

The inserts made of different steel grades and surfaced layers were replaced for each test. The cutterhead was designed to have two cutting edges, to avoid the imbalance that can appear with one insert, however while two experimental inserts were mounted [10], only one was tested. An indirect method was used to change the thickness of chips through the feed per one insert $f_{z}=0.50 \mathrm{~mm}$ and $1.00 \mathrm{~mm}$. The cutting speed was constant for all tested samples $n_{c}=31 \mathrm{~m} / \mathrm{s}$. The rotating frequency of the cutterhead measured with an accuracy of $10 \mathrm{~min}^{-1}$ using a Tachometer Stroboscope SC-5 was $n=5790 \mathrm{~min}^{-1}$.

\section{RESULTS AND DISCUSSION}

The wear measurement was based on the determination of the edge recession (cutting edge radius, edge recession, and nose width) after each defined cutting length (effective cutting path of the blade).

The wear test results of two experimental and two commercial inserts showed that there are three phases, which characterize the evolution of the insert wear recession: running (intensive wear), linear wear (stable), and vital wear (tool failure). It can be stated that for each type of insert, the running period was up to $800 \mathrm{~m}$ of cutting length due to intensive wear [2]. The results, as shown in Fig. 3, indicate that further wear evolution of inserts was relatively linear or stable.

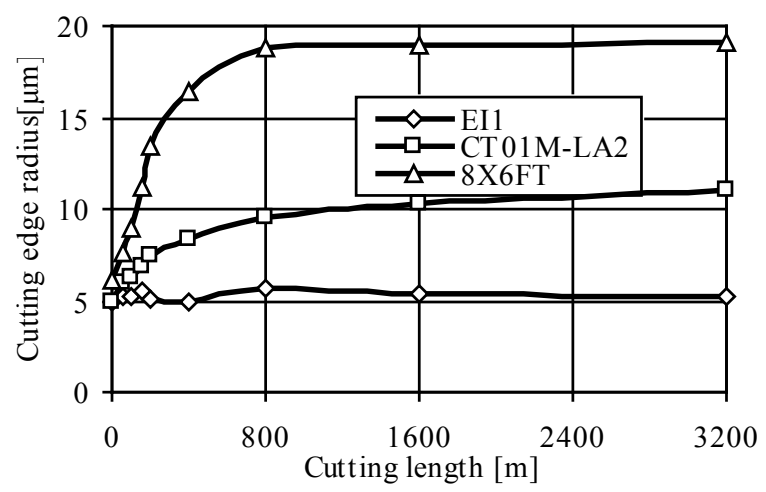

Fig. 3. Variation of the cutting edge radius for the feed per insert $\left(f_{z}=1.0 \mathrm{~mm}\right)$
In Fig. 3 there is a clear trend towards an increase in the inserts cutting edge radius with increasing cutting length. The cutting edge radius of the surfaced and subsequently hammered insert EI1 showed the lowest wear evolution when compared with commercial inserts: $5.22 \mu \mathrm{m}$. The results of the cutting edge test are in line with those of the previous test, as the tendency of wear of the EI2 inserts was the same: $5.35 \mu \mathrm{m}$. The cutting edge radius of the industrial insert made of CT01M-LA2 was $11.2 \mu \mathrm{m}$, while the maximum wear values were achieved on 8 X6FT inserts with $19.8 \mu \mathrm{m}$. Previous studies have attempted to explain why tools with a cutting edge radius of more than $25 \mu \mathrm{m}$ cannot be used for machining any more [5].

The smallest edge recession was noticed when testing surfaced insert EI2 (Fig. 4).

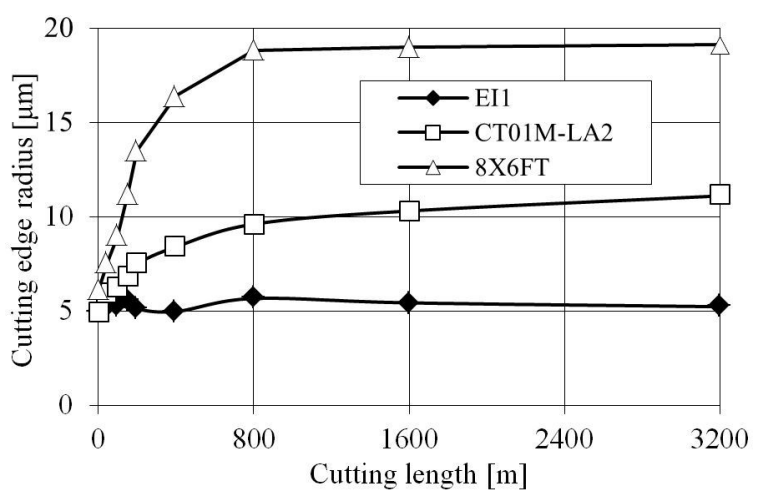

Fig. 4. Edge recession for the feed per insert $\left(f_{z}=0.5 \mathrm{~mm}\right)$

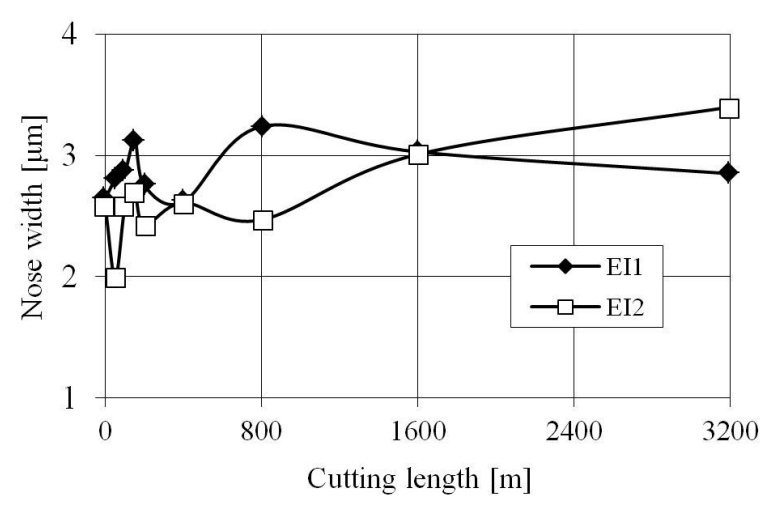

Fig. 5. Nose width growth of surfaced inserts

There was no significant difference between edge recession of surfaced inserts EI1 and EI2 $(10.66 \mu \mathrm{m}$ and $10.75 \mu \mathrm{m}$ respectively), while the edge recession of industrial inserts was $\sim 20$ to $35 \mu \mathrm{m}$. Overall, these results indicate that the edge recession of experimental tools was 2 to 3 times lower. 
As shown in Fig. 5, the nose width test was used to analyse tool wear. The milling test was interrupted at defined intervals of cutting length in the same way as for previous tests.

Average tool wear or blunting can be defined as the difference between the resultant nose width and the initial nose width.

Cutting tool temperature is another important factor affecting tool wear in wood machining, because the hardness, toughness, and chemical properties of tool material degrade when the tool's temperature increases [11]. Continuous plastic deformation and shear during chip formation generates thermal energy and friction, which appear on the rake and clearance face of the tool, at the same time there is also friction between the sample and the back face of the tool. The heat generated is transferred to the cutting tool and work sample. This heat has a negative effect on the quality and accuracy of the machined products and on the main parameters of cutting: cutting speed, depth of cut, blunting and cutting power. Consequently, the cutting power of all inserts was tested over the whole cutting length (Figs. 6 and 7 and Table 6).

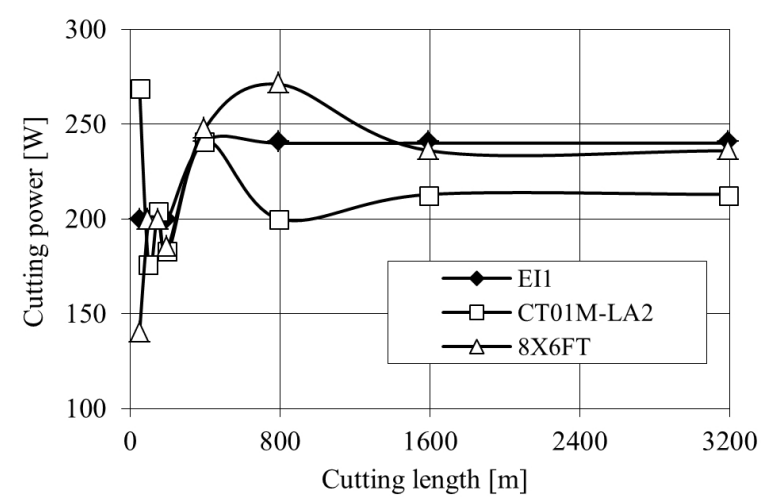

Fig. 6. Cutting power of inserts for $f_{z}=1.0 \mathrm{~mm}$

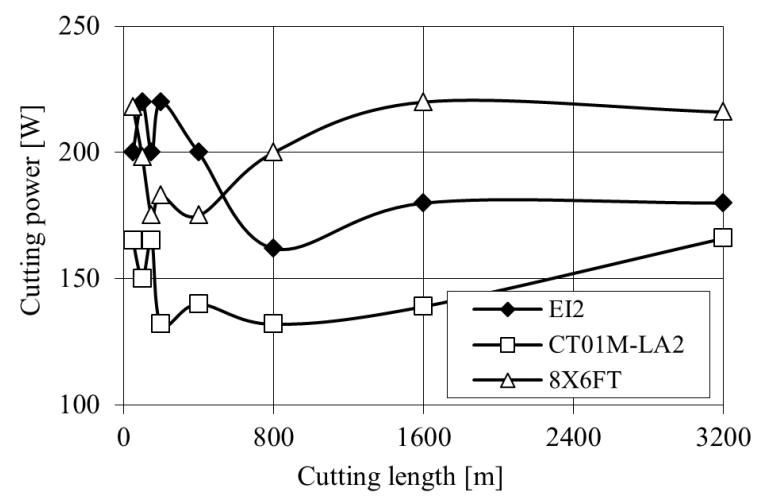

Fig. 7. Cutting power of inserts for $f_{z}=0.5 \mathrm{~mm}$
The values of cutting power up to $400 \mathrm{~m}$ of cutting length were high because of crumbling of the top of blade's cutting edge [12]. At this stage of machining the cutting edge radius grew rapidly as well. Linear or stable cutting power intensity was observed for all inserts at cutting lengths from 1200 $\mathrm{m}$ to $3200 \mathrm{~m}$. Wear by crumbling of inserts blades was displaced by a plastic wear phase. Surfaced inserts EI1 and EI2 showed very similar results for cutting power, therefore they can be used for machining of wood.

Table 6. Cutting power of inserts $(W)\left(f_{z}=0.5 \mathrm{~mm}\right)$

\begin{tabular}{lcccccccc}
\hline & \multicolumn{8}{c}{ Cutting length [m] } \\
\cline { 2 - 9 } & 50 & 100 & 150 & 200 & 400 & 800 & 1600 & 3200 \\
\hline El2 & 200 & 220 & 200 & 220 & 200 & 162 & 180 & 180 \\
\hline 1 * & 218 & 198 & 175 & 183 & 175 & 200 & 220 & 216 \\
\hline 2 ** & 165 & 150 & 165 & 132 & 140 & 132 & 139 & 166 \\
\hline 1 * $8 X 6 \mathrm{FT} ; 2$ ** CT01M-LA2 \\
\hline
\end{tabular}

\section{CONCLUSIONS}

The lowest cutting edge radius occurred on surfaced and additionally plastically deformed insert EI1; the cutting edge radius after $3200 \mathrm{~m}$ of cutting length was $5.22 \mu \mathrm{m}$, while for unhammered EI2 it was $5.35 \mu \mathrm{m}$. In summary, these results show 3 to 4 times lower wear than commercial tools.

Better wear performance was achieved by testing the edge recession of surfaced inserts EI1 and EI2. In summary, edge recession of the suggested experimental tools was 2 to 3 times lower.

The most obvious finding to emerge from the analysis is that the relatively hard coatings (55 to 57 HRC) surfaced on soft plain carbon steel can replace some commercial inserts made of high speed tool steels for use in oak wood machining, thus reducing friction and wear of the wood cutting tool.

\section{REFERENCES}

[1] Warcholinski, B., Gilewicz, A., Ratajski, J. (2011). Cr2N/ CrN multilayer coatings for wood machining tools. Tribology International, vol. 44, no. 9, p. 1076-1082, D0l:10.1016/j. triboint.2011.05.004.

[2] Vobroucek, J. (2015). The influence of milling tool geometry on the quality of the machined surface. Procedia Engineering, 25th DAAAM International Symposium on Intelligent Manufacturing and Automation, vol. 100, p. 1556-1561, D0l:10.1016/j.proeng.2015.01.528.

[3] Faga, M.J., Settineri, L. (2006). Innovative anti-wear coatings on cutting tools wood machining. Surface and Coatings Technology, vol. 201, no. 6, p. 3002-3007, D0l:10.1016/j. surfcoat.2006.06.013. 
[4] Djouadi, M.A., Beer, P., Marchal, R., Solokowska, A., Lambertin, M., Precht, W., Nouveau, C. (1999). Antiabrasive coatings: application for wood processing. Surface and Coating Technology, vol. 116-119, p. 508-516, Dol:10.1016/S02578972(99)00236-4.

[5] Endler, I., Bartsch, K., Leonhardt, A., Scheibe, H.J., Ziegele, H., Fuchs, I., Raatz, Ch. (1999). Preparation and wear behaviour of woodworking tools coated with superhard layers. Diamond and Related Materials, vol. 8, no. 2-5, p. 834-839, DOl:10.1016/S0925-9635(98)00359-8.

[6] Gilewicz, A., Warcholinski, B., Myslinski, P., Szymanski, W. (2011). Anti-wear multilayer coatings based on chromium nitride for wood machining tools. Wear, vol. 270, no. 1-2, p. 32-38, D0l:10.1016/J.wear.2010.09.002.

[7] Ambroza, P., Bockus, S., Kavaliauskiene, L. (2013). Formation of build up layers microstructure by arc automatic overlay welding using secondary raw material powders. Archives of Metallurgy and Material, vol. 58, no. 2, p. 549-553, DOl:10.2478/amm-2013-0034.

[8] Keturakis, G., Lisauskas, V. (2010). Influence of the sharpness angle on the initial wear of the wood milling knives. Materials Science (Medžiagotyra), vol. 16, no. 3, p. 205-209.
[9] Keturakis, G., Juodeikiene, I. (2007). Inverstigation of Milled wood surface roughness. Materials Science (Medžiagotyra), vol. 13, no. 1, p. 47-51.

[10] Aknouche, H., Outahyon, A., Nouveau, C., Marchal, R., Zerizer, A., Butaud, J.C. (2009). Tool wear effect on cutting forces: In routing process of Aleppo pine wood. Journal of Materials Processing Technology, vol. 209, no. 6, p. 2918-2922, DOI:10.1016/j.jmatprotec.2008.06.062.

[11] Darmawan, W., Gottlober, Ch., Oertel, M., Wagenfuhr, A., Fischer, R. (2011). Performance of helical edge milling cutters in planning wood. European Journal of Wood and Wood Products, vol. 69 , no. 4, p. 565-572, D0l:10.1007/s00107010-0517-8.

[12] Horman, I., Busuladzic, I., Azemovic, E. (2014). Temperature influence on wear characteristics and blunting of the tool in continuous wood cutting process. Procedia Engineering, 24th DAAAM International Symposium on Intelligent Manufacturing and Automation, vol. 69, p. 133-140, D0l:10.1016/j.proeng.2014.02.213. 